\title{
Nota anatomica sobre um caso de rins concrescentes
}

\author{
pelos \\ Drs. BENJAMIN BAPTISTA \\ Professor da Faculdade de Medicina do Rio de Janeiro.

\section{E CEZAR GUERREIRO.} \\ Assistente do Instituto Oswaldo Cruz
}

(Com as estampas 1-2).

Necropsiando, no Serviço de Anatomia Pathologica, que o Instituto OSWALDO CRUZ mantém annexo á Santa Casa de Misericordia, o cadaver de A.V.P., de 54 annos, hespanhol, fallecido no Serviço Clinico do Dr. SYLVIO MONAZ, foi dado a um de nós encontrar uma anomalia renal que, por sua relativa raridade, é digna de registo.

Tratava-se dum individuo fallecido duma cachexia carcinomatosa, occasionada por um neoplasma desse typo, localizado na parotida esquerda com metastases gastricas e hepaticas.

Ao lado desse quadro, tal individuo apresentava tambem uma inlensa aortite syphilitica, com alguns pontos de endaortite calcificante na crossa e volumosas exostoses dos corpos vertebrais, especialmente dos da 2a. e 3 a vertebras dorsaes e dos da 1a e 2a lombares.

Examinando o apparelho urinario notámos a ausencia do rim do lado direito. No lado esquerdo, occupando a região renal encontrámos o rin respectivo muito alongado, dirigindo-se de cima para baixo e de fóra para dentro, preenchendo não sómente a loja renal, como atravessando o estreito superior da bacia e a parte mais superior do estreito inferior. Esta peça media 24 centimetros de comprimento, 7 centimetros de largura na parte superior e 6 centimetros na parte inferior.

Examinando a peça verificámos ser ella constituida de duas porções, uma superior e outra inferior, ligadas por um pediculo de 3 centimetros de largura.

$\mathrm{Na}$ parte anterior da referida peça, verificámos que, na face anterior da porção superior, encontra-se uma depressão analoga á que existe no bordo concavo do rim normal. Tratava-se, portanto, dum seio renal, por isso que ahi encontrámos a penetração da arteria renal que se dividia em 3 ramos, a sahida de 3 veias que depois constituiam a veia renal e um longo bassinete do typo 
ramificado, ao qual succedia um uretere.

$\mathrm{Na}$ face posterior, verificámos que, na parte correspondente á porção inferior, existia uma depressão si bem que menos accentuada. Esta depressão, que representa um segundo seio renal, abrigava um bassinete com 3 ramos de origem, partindo delle um uretere. Ao nivel deste segundo seio renal penetrava uma arteria que se dividia em dois ramos.

Praticado o exame do bordo externo, que era ligeiramente convexo, verificámos ao nivel de sua parte media, um sulco bem pronunciado, separando de modo incompleto a peça anatomica em duas porções: uma superior, outra inferior ligadas por um pediculo. $O$ bordo interno que era ligeiramente concavo, apresentava um sulco na sua parte media e ao nivel deste sulco, uma arteria que se dividia em 4 ramos dos quaes um penetrava na parte inferior da primeira porção da peça e outro na parte superior da segunda porção da peça, distribuindose os restantes no pediculo.

Sobre a extremidade superior desta peça anatomica estava situado o orgão suprarenal esquerdo, sendo que o direito existia tambem em situação normal.
Praticado um córte do bordo externo para o bordo interno, no orgão superior, verificámos que o uretere fazia seguimento a um bassinete formado pela reunião de dois ramos: um superior e outro inferior. O ramo superior recebia tres ramos secundarios que eram formados pelos calices das pyramides que occupavam os dois terços superiores do orgão. O ramo inferior recebia tres ramos que provinham dos calices correspondentes ás pyramides do terço inferior do orgão.

Praticado um córte da porção inferior da peça, do bordo interno para o bordo externo, verificámos que, nesta peça, existiam dois bassineies cada um delles situado num seio renal. O bassinete superior partia do seio localizado ao nivel do terço superior da face posterior da peça e era formado pela reunião de dois que resultavam, por sua ve $z$, da convergencia dos calices das pyramides situadas ao nivel do terço superior e do terço médio. O segundo bassinete estava situado ao nivel do segundo seio renal, localizado no bordo externo da peça, no ponto de união do terço medio com o terço inferior. Este segundo bassinete, que era sessil, recebia tres ramos pro venientes dos calices das pyramides do terço inferior da peça. 
Explicação das estampas.

Estampa 1.

Fig. 1-Face anterior.

Fig. 2-Face posterior.

Fig. 3-Bordo externo.
Fig. 4-Bordo interno.

Estampa 2.

Fig. 1-Porção superior cortada do bordo externo para o interno.

Fig. 2-Porção inferior cortada do bordo interno para o externo. 

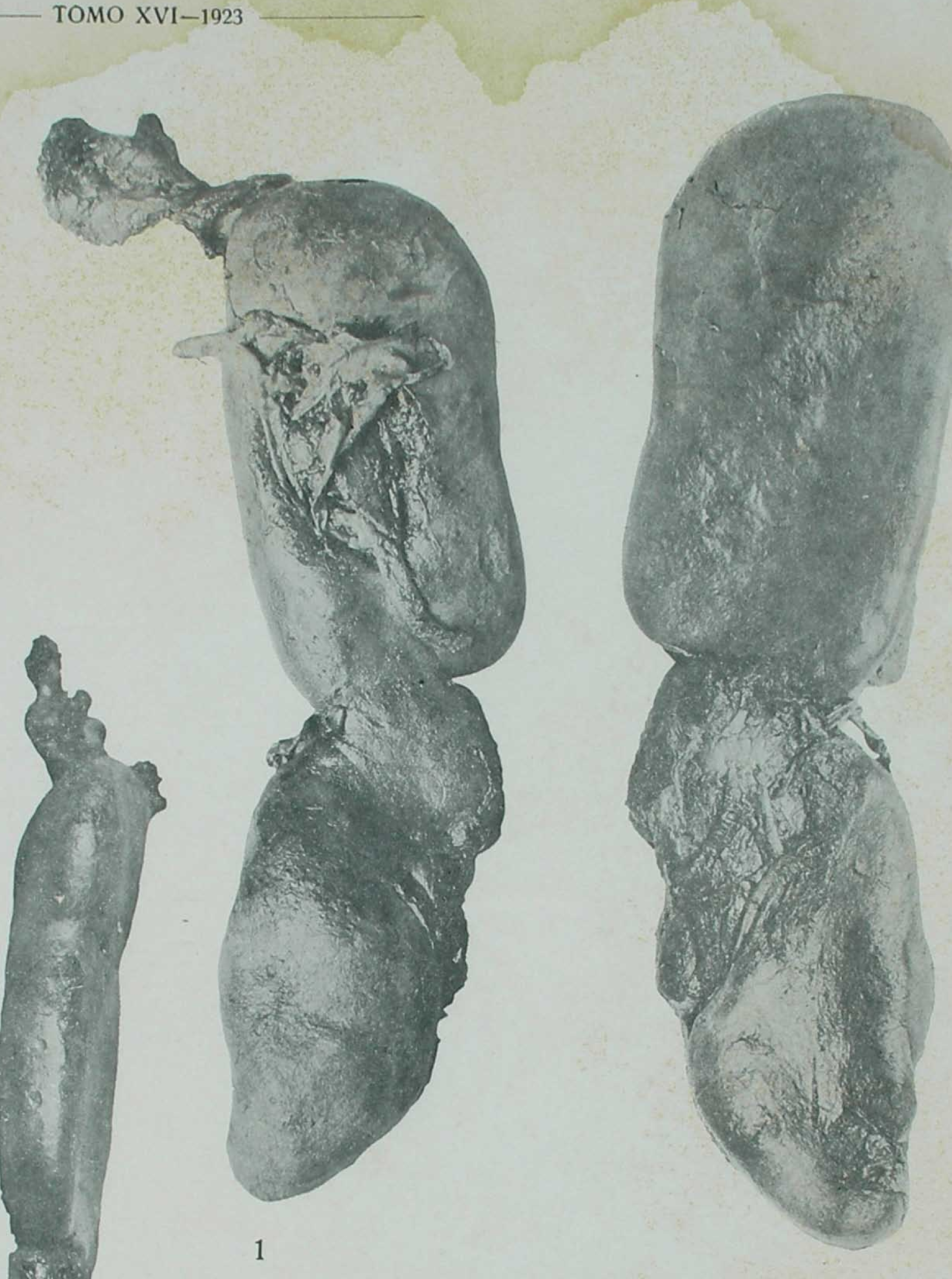

2

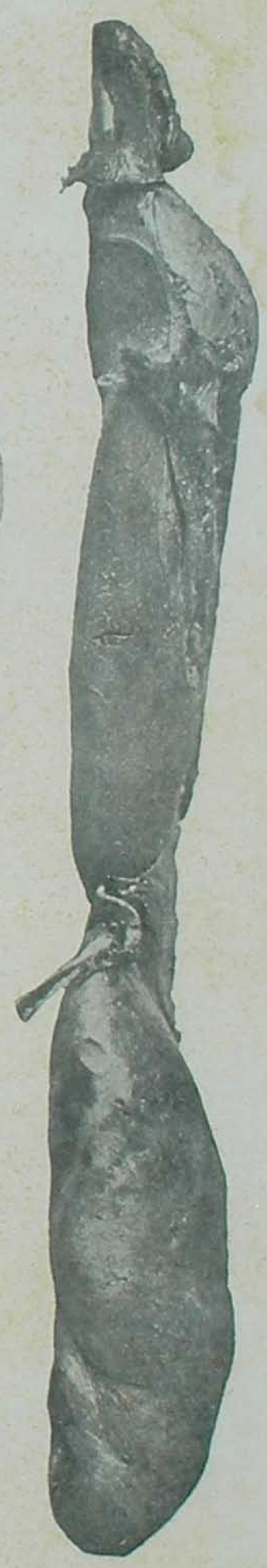




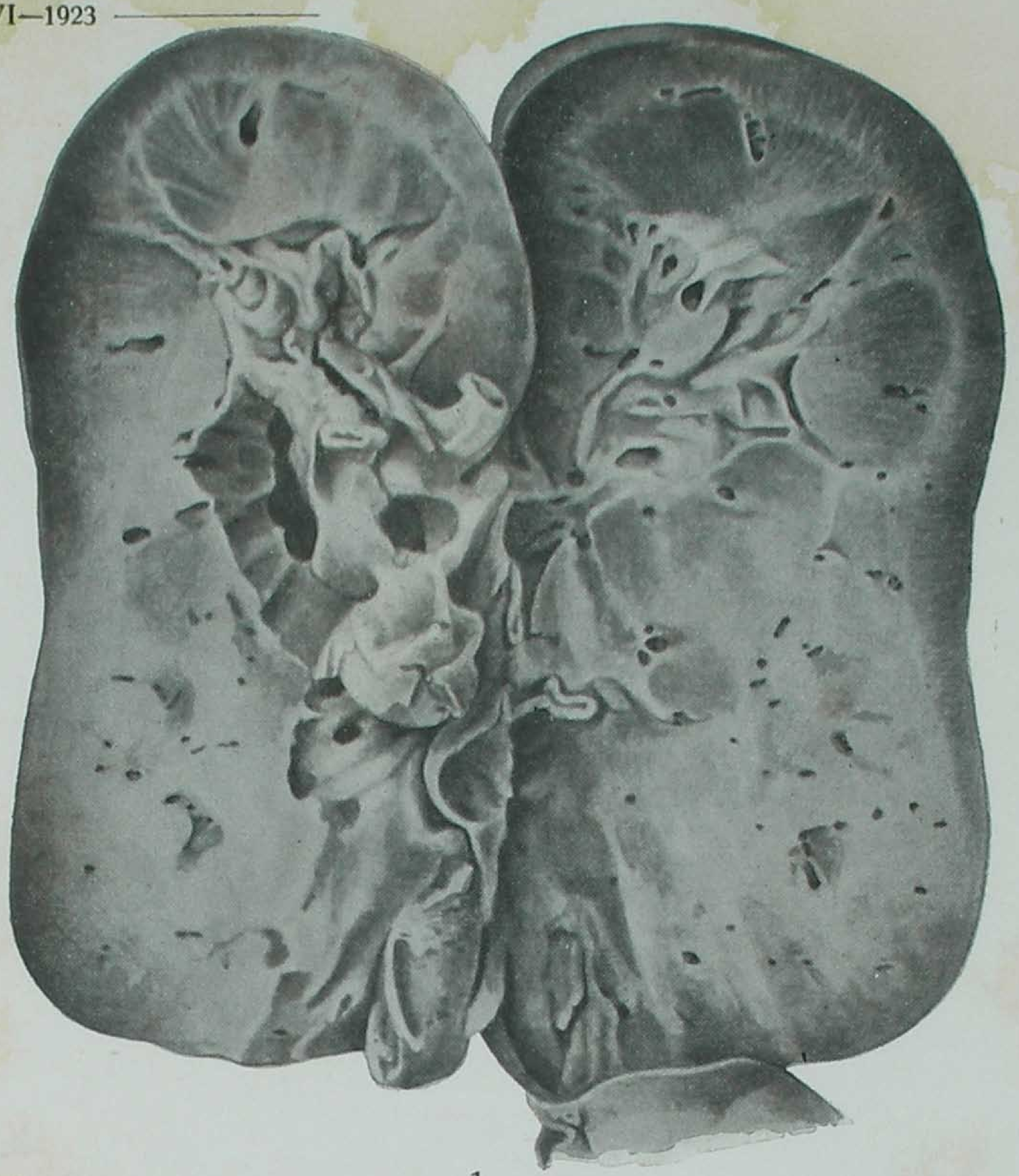

1

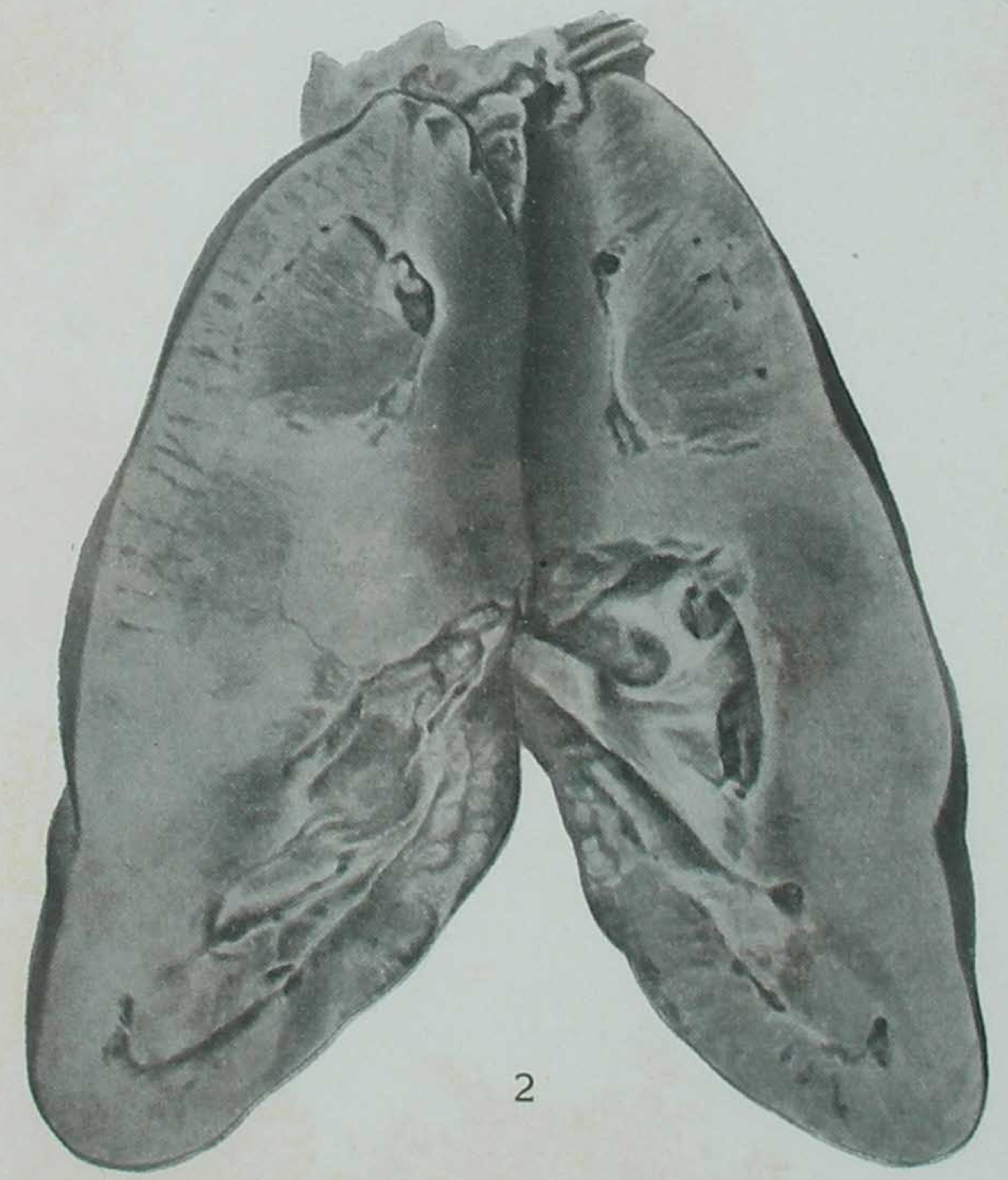

